\title{
Correspondence
}

\section{Citation errors - there is still much to be done}

To the Editor:

It is encouraging to see that the incidence of mis-citation in the Canadian Journal of Anaesthesia has decreased dramatically. ${ }^{1,2}$ The decision of your editorial board to require authors of accepted articles to provide photocopies of the first page of each quoted reference is very effective. This practice should minimise "perpetual error" - citation reproduced from another article along with the existing errors, because the authors, at least, should see a copy of the original article. A historical example of this type of error is the repeated citation of an article by purportedly a Czech doctor, $\mathrm{O}$. Uplavici. Dr. O. Uplavici's name had been cited for more than 55 years before he was "buried" by another author. ${ }^{3} \mathrm{O}$. Uplavici was apparently not an author's name, but the title of the article (although we have not checked the original source!).

Misquotation is a more serious problem. Major errors of quotations, such as ones which are not substantiated by, not related to, or contradictory to, the article quoted, displease the authors and mislead the readers. Evans $e t$ al. found major errors of quotation in 37 of 137 quoted references. ${ }^{4}$. Perpetual quotation errors produce a false "accepted fact," which is very hard to correct. Some errors may be innocent misunderstanding of the original source, but sometimes such misinterpretations are made intentionally, in particular, when an author quotes his or her own previous work.

Doctor Bevan and Ms. Purkis reiterate that editors, publishers and authors share the responsibility for providing accurate manuscripts. We suggest that it is also the reader's responsibility to verify the accuracy of a quoted statement (by checking the original paper) before believing such a statement and allowing it to influence clinical practice. Readers should be encouraged to point out and correct misleading quotation errors, an important function of a journal for which the correspondence sections are provided. Letters should not, however, just point out the error, but should provide the full message in order to prevent both perpetual errors and false accepted facts.

Taking our own thesis to heart, we would like to point out that there are three major errors in citations and two minor misquotations from the study by Evans et al. in your Editorial on this topic."1 One journal's name (Surgery, Gynecology \& Obstetrics) is also wrong. Humans are born to make mistakes, but should never give up the attempt to conquer this tendency.

Takashi Asai MD

M.D. Vickers FRCA

Department of Anaesthetics and Intensive Care Medicine University of Wales College of Medicine

Heath Park, Cardiff

United Kingdom

\section{REFERENCES}

1 Bevan DR, Purkis JM. Citation errors can be reduced (Editorial). Can J Anaesth 1995; 42: 367-9.

2 Asano $M$, Mikawa $K$, Nishina $K$, Maekawa $N$, Obara $H$. Improvement of the accuracy of references in the Canadian Journal of Anaesthesia. Can J Anaesth 1995; 42: 370-2.

3 Dobell C. Dr. O. Uplavici (1887-1938). Parasitology 1938; 30: 239-41.

4 Evans JT, Nadjari HI, Burchell SA. Quotational and reference accuracy in surgical journals: a continuing peer review problem. JAMA 1990; 263: 1353-4.

\section{Acute respiratory distress in a parturient under effective epidural analgesia}

To the Editor:

We describe a rare complication in a young primigravida who was healthy except for infrequent asthamtic attacks, the last over a year ago when an inhaler had been prescribed. Her prenatal course was uneventful as were her labour and spontaneous vaginal delivery under satisfactory lumbar epidural analgesia. During repair of the episiotomy, with the sensory level at $T_{10}$, she became fidgety and increasingly talkative when, suddenly, she developed

*Professor Bevan and Ms. Purkis quote from the study of Evans et al. that "thirteen quoted articles could not be traced and, in the remaining 37, they found major errors in 13 and minor errors in 41." In fact, although Evans et al. twice state that they selected 50 references, it is clear from various calculations and is once actually stated, that they selected 150 references and found major errors in 13 . In the remaining 137 references, there were 41 minor errors. ${ }^{4}$ 